\title{
Food industry sponsorship of academic research: investigating commercial bias in the research agenda
}

\author{
Alice Fabbri ${ }^{1,2}$, Taylor J Holland ${ }^{2}$ and Lisa A Bero ${ }^{2, *}$ \\ ${ }^{1}$ Centre of Research in Medical Pharmacology, University of Insubria, Varese, Italy: ${ }^{2}$ Charles Perkins Centre and \\ School of Pharmacy, Faculty of Medicine and Health, The University of Sydney, Camperdown, NSW 2006, \\ Australia
}

Submitted 8 March 2018: Final revision received 30 May 2018: Accepted 13 July 2018: First published online 30 August 2018

\begin{abstract}
Objective: To identify scientific publications that result from food industry-funded projects on human health and to characterize their research topics to assess the potential for bias in the research agenda.

Design: Cross-sectional analysis.

Setting/Subjects: Food industry-supported projects related to human health were identified from food company websites; publications resulting from the food industry-sponsored projects were identified through a PubMed search.

Results: Of ten companies analysed, only two (Coca-Cola and the Mars Center for Cocoa Health Science) provided a list of research projects with sufficient detail for analysis. Among the 204 publications resulting from thirty-seven disclosed research projects, the most common topic was physical activity (40.7\%), while highly processed foods were analysed in $10.8 \%$ of the publications. Twenty-two publications (10.8\%) focused on research integrity or research methods. Conclusions: Publications resulting from Coca-Cola- and Mars-sponsored research appear to skew the evidence towards solutions that favour industry interests by focusing on food components that can be manipulated and marketed by food companies. These food industry-funded publications can also distract from nutrition as a health issue by diverting public and policy attention to physical activity. Shaping the debate around scientific methods can be another strategy that corporations use for their benefit to raise doubts about the methods used in nonindustry sponsored research.
\end{abstract}

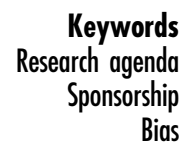

Funding of research is a core activity for food companies and serves multiple purposes beyond simply developing new products. Scientific results suggesting that a company's products have health benefits can attract publicity in the media, influence consumers' choices and shape nutrition and clinical guideline development ${ }^{(1)}$.

In addition to in-house science, food companies are increasingly funding research conducted with universitybased researchers ${ }^{(2,3)}$. Strategic partnerships between researchers and the corporate world are actively encouraged by governmental agencies and academic institutions as a tool to accelerate innovation and guarantee research translation $^{(4,5)}$. However, these arrangements pose high risks of bias to the research environment and consequently to public health. Evidence across several fields has shown that corporate sponsorship can bias the design, conduct and publication of research ${ }^{(6-8)}$. For example, analyses of pharmaceutical industry-funded studies found that industry sponsorship is associated with selective reporting of outcomes that favour the sponsor $^{(9,10)}$. These practices can threaten the credibility of the evidence on which decisions are based.

Although bias in study methods and in reporting of research results are most often examined, bias can affect the outcome of research by influencing other parts of the research process. For example, industry sponsorship can influence the very initial stage of the cycle of research, namely the research agenda, defined as how research priorities, topics and questions are selected and framed. Biases in the research agenda have already been documented across different industry sectors; for example, in the 1980s the tobacco industry financed research projects on general indoor air quality to divert attention from passive smoking as an indoor air pollutant. The findings of these studies were presented in legislative settings to support the tobacco industry position that other substances in indoor air were more harmful than second-hand smoke, thus hindering the development of smoking policies ${ }^{(11)}$. 
Bias in the research agenda has not been extensively studied in the area of nutrition ${ }^{(12)}$. This bias can be particularly relevant in nutrition as the focus on certain research questions can produce results that support specific policy responses, which have the potential to affect population health. For example, more research on physical activity interventions to control obesity compared with less research on interventions aimed at changing the food environment could support policy responses focused on physical activity, diverting attention from diet. Recent media has suggested that a multinational food company attempted to influence the obesity research agenda by funding research that highlighted the impact exercise plays in maintaining body weight, thereby downplaying the role of food products ${ }^{(13)}$. Corporate manipulation of the research agenda has also been described in analyses of industry documents that showed how the sugar industry shaped the research agenda on dental caries and CVD to deflect attention from the role of sugar ${ }^{(14,15)}$.

Moreover, according to some researchers, the nutritionally reductive approach to food that has characterized nutrition research in the past decades has been recently co-opted by food companies and used as an effective means of promoting their products ${ }^{(16)}$. This approach, called 'nutritionism', is characterized by a reductive focus on individual nutrients, in isolation from the foods and diets in which we find them. Commercial interests can be an important driver of this nutrient focus; food companies can indeed benefit from this approach by claiming that products containing a specific nutrient yield some health advantages ${ }^{(1)}$. We previously used this conceptual framework to quantitatively explore the association between funding sources and research topics in samples of published randomized controlled trials ${ }^{(17)}$ and cohort stu$\operatorname{dies}^{(18)}$ on nutrition and obesity. The analysis of trials showed that $66.7 \%$ of the food industry-funded studies focused on interventions involving manipulations of nutrients rather than foods or dietary patterns ${ }^{(17)}$. Among cohort studies, the most represented topic in studies funded by food companies was nutrients (37.5\%), followed by foods or food groups $(31.3 \%)^{(18)}$. Although no statistically significant differences in research topics by funding sources were observed, both those analyses were hindered by the low level of disclosure of food industry sponsorship in published articles.

Therefore, in the present study, instead of relying on funding disclosures in published nutrition research articles, we first identified major commercial sponsors of nutrition research. We sought to identify research projects funded by these companies and then track their resulting publications. We aimed to determine the extent to which food industry-funded academic research projects on human health were published in the scientific literature and to characterize the research topics of the publications, thereby to assess the potential for bias in the research agenda.
Based on our studies of the research topics of published nutrition articles, limited analyses of sugar industry documents and sociological analyses of the history of nutrition science, we expected the industry's research agenda to be biased towards questions that address potential for profits, not public health. We expected food companies to fund research on nutrient-specific questions and not to fund studies that assess nutrients or foods in terms of the level of processing ${ }^{(16,17)}$. We also hypothesized that food companies would tend to fund research on non-nutrition related topics and their association with health outcomes as a way of distracting from potential harms of their products $^{(13,19)}$.

\section{Methods}

\section{Overview}

We used a cross-sectional study design to first identify food industry-funded projects and then to identify scientific publications resulting from those projects.

\section{Sampling}

Two investigators independently analysed the websites of the ten companies that control the majority of the packaged food and beverage market: Associated British Foods, Coca-Cola, Danone, General Mills, Kellogg's, Mars, Mondelez (formerly Kraft), Nestlé, PepsiCo and Unilever ${ }^{(20,21)}$. These companies are the focus of an Oxfam campaign aimed at building a more sustainable food system and have been chosen based on overall revenues and other indicators of companies' size such as sales, profits, assets and market share ${ }^{(21)}$. If the company had multiple branches, we analysed the websites of the branches located in regions where English is a primary, official language (Australia, Great Britain, New Zealand and North America; Coca-Cola has a 'North American Branch' website and the 'Transparency list' of funding provided for research includes both US and Canadian recipients).

Between December 2016 and February 2017, two investigators independently searched each company website for specific, company-funded research projects. From each website, the homepage, the sections dedicated to Research \& Innovation, and the most recent annual report were analysed to find information on research sponsorship (see online supplementary material, Supplementary File 1 for additional details on the website search). If a list of research projects was not available on the company headquarters website, we searched affiliated entities such as company research institutes or facilities. We did not analyse research institutes that conduct purely in-house research as our focus was on industry-funded research with external academic partners. We did not analyse the websites of industry-affiliated foundations or charities. 


\section{Identifying company-funded projects}

We identified research projects by searching for details of sponsorship of scientific research conducted with universitybased researchers. From the website, we recorded the titles/ descriptions of the project, the participating universities, and the project's Principal Investigator(s) (PI) or Scientific Director(s). We did not extract data from broad descriptions of collaborations with academic partners that made no reference to a specific research project, the date it started or its academic PI, as there was not enough information to track the publication of such research.

Two researchers independently screened the list of sponsored projects according to the following criteria. We included:

1. research projects related to human health;

2. projects that named an academic PI; and

3. projects for which it was possible to identify a start date.

We excluded:

1. purely in-house research; and

2. projects related to animal nutrition, agricultural and environmental science, and product safety research.

Discrepancies in extracted information were discussed with the third author and resolved.

\section{Identifying company sponsored scientific publications}

For all sponsored research projects meeting our inclusion criteria, we attempted to identify scientific publications that resulted from the projects. We considered a publication as related to the industry-funded project if it matched the project title and was authored by the academic PI disclosed on the company website. We searched PubMed for all articles authored by these PI. The search dates were from the date of funding to December 2016.

All the publications were screened by two investigators for relevance to the title of the industry-funded project. Since our focus was on identifying research, we included randomized controlled trials, observational studies, qualitative studies, narrative reviews, analysis articles and systematic reviews/meta-analyses. Symposium proceedings were included only for one academic PI who received 'Educational grants for scientific symposia and publications'. Publications with multiple industry-supported PI were counted only once.

For each publication that we deemed related to the title of an industry-funded project, we extracted information on the disclosed source(s) of funding. Publications that were related to the topic of the industry-funded project but disclosed a different funding source (e.g. a governmental agency) were excluded from further analysis. All the other publications were classified as: (i) funded by the food company that disclosed sponsorship of the project on its website (even when the company was one among several funders); or (ii) no funding disclosure. In case of no funding disclosure, the conflict of interest disclosure in the publication was analysed and if the PI disclosed receiving 'unrestricted research grants' from the company, the publication was classified as industry-funded.

\section{Data extraction}

The following data were collected from each included publication.

1. Identifying information: title, journal name, year of publication.

2. Disclosed funding source: classified as food companyfunded or not.

3. Study design.

4. Research topics: to characterize the research agenda of the funded projects, we coded the main research question/primary hypothesis (if stated) of each publication. The taxonomy we used to code research topics was inspired by previous research on bias in the nutrition research agenda ${ }^{(17,18)}$ and was further refined by iterative coding of a sample of publications (Table 3). Each publication could be coded under multiple topics.

5. Direction of conclusion: if the publication focused on a product or a component of a product marketed by the sponsor, the conclusions were coded as: favouring the sponsor's product (e.g. the authors concluded that the product had beneficial health effects or cast doubts on the evidence linking the product to health harms); not favouring the sponsor's product (e.g. the authors concluded that the product did not bring beneficial health effects); neutral (e.g. the authors discussed both positive and negative health effects of the product); or not applicable (e.g. the article did not have a conclusion that could be interpreted).

\section{Analysis}

We report descriptive statistics on the number of projects identified from the industry websites and the number of publications resulting from each project. We also report

Table 1 Number of sponsorships and total financial support for health and well-being scientific research from Coca-Cola, identified by searching the company's websites

\begin{tabular}{lcc}
\hline Branch & $\begin{array}{c}\text { Research (no. of } \\
\text { sponsorships) }\end{array}$ & $\begin{array}{c}\text { Total financial support } \\
\text { for research (\$US) }\end{array}$ \\
\hline Australia & 2 & 140861.98 \\
Great Britain & 10 & 1250988.30 \\
New Zealand & 2 & 8509.60 \\
North America & 44 & 22380496 \\
TOTAL & 58 & 23780855.88
\end{tabular}

Currencies were converted to $\$$ US using www.xe.com (date of conversion: 23 March 2017). 
the characteristics of identified publications, including their research topics.

\section{Results}

\section{Industry-sponsored research projects}

Out of the ten companies analysed, only two (Coca-Cola and the Mars Center for Cocoa Health Science) provided a list of research projects with sufficient detail for our analysis. Several companies provided a narrative description of their collaborations with academic institutions in their annual reports or on their websites. However, these

Table 2 Study design of publications ( $n$ 204) resulting from research projects related to human health funded by Coca-Cola and Mars, identified through a PubMed search, December 2016

\begin{tabular}{lrr}
\hline & $n$ & $\%$ \\
\hline Observational study & 120 & 58.8 \\
Narrative review & 31 & $15 \cdot 2$ \\
Randomized controlled trial & 23 & 11.3 \\
Systematic review/meta-analysis & 8 & 3.9 \\
Laboratory study & 3 & 1.5 \\
Qualitative study & 2 & 1.0 \\
Experimental non-randomized study & 1 & 0.5 \\
Other & 16 & 7.8 \\
TOTAL & 204 & $100 \cdot 0$ \\
\hline
\end{tabular}

descriptions were too vague to be linked to a specific study or PI. Other companies provided a selected list of scientific publications, but we could not determine if this was a representative sample of the company's funded research. Thus, we did not include them in our analysis.

\section{Coca-Cola}

The websites of Coca-Cola Australia, Great Britain, New Zealand and North America provided an extensive list of the funding awarded to different organizations and institutions from January 2010 onwards. The list included the study title/partnership name, the recipient organization, and the amount and date of funding. Most of the disclosed funding went to partnership programmes with charities and community organizations (\$US 123794234.63 ), while fifty-eight projects were defined as scientific research (Table 1)

The level of transparency varied by region. Since CocaCola North America was the only division that provided a list of PI for most of the research sponsorships, we focused only on that company's branch. According to the CocaCola North America transparency list, there were a total of 1242 sponsorships awarded to different organizations and institutions from 1 January 2010 to 30 June $2016^{(22)}$. Of these, forty-four were classified by the company as 'research'. Coca-Cola provided the name of the PI for

Table 3 Research topics of publications ( $n$ 204) resulting from research projects related to human health funded by Coca-Cola and Mars, identified through a PubMed search, December 2016

\begin{tabular}{|c|c|c|c|}
\hline Topic & Examples from the included publications & $n$ & $\% *$ \\
\hline \multicolumn{4}{|l|}{ Physical activity/nutrition topics } \\
\hline Physical activity/sedentary behaviours & $\begin{array}{l}\text { Exercise, cardiorespiratory fitness, musculoskeletal fitness, muscle strength, sedentary } \\
\text { behaviours }\end{array}$ & 83 & $40 \cdot 7$ \\
\hline Energy & Calories, energy flux, energy balance, energy intake/expenditure & 15 & $7 \cdot 4$ \\
\hline Nutrients/components & Fat, protein, carbohydrates, sugars, cocoa flavanol & 45 & $22 \cdot 1$ \\
\hline Food groups & Vegetables, fruits, grain foods & 5 & 2.5 \\
\hline Dietary pattern & $\begin{array}{l}\text { Overall dietary pattern or cuisine (e.g. Mediterranean diet), dietary scores that measure } \\
\text { diet quality looking at multiple components }\end{array}$ & 4 & $2 \cdot 0$ \\
\hline Highly processed foods & Sugar-sweetened beverages, high-energy snacks, fast foods, added sugar & 22 & $10 \cdot 8$ \\
\hline Functional foods & Fortified beverages & 1 & 0.5 \\
\hline Dietary behaviours & $\begin{array}{l}\text { Eating behaviour, appetite regulation, hunger/satiety, self-control of food intake, timing of } \\
\text { meals, snacking, portion size }\end{array}$ & 5 & 2.5 \\
\hline \multicolumn{4}{|l|}{ Other topics studied } \\
\hline Psychological factors & Depression, happiness & 8 & 3.9 \\
\hline Cognitive function & Cognitive performance, academic performance, cognitive impairment & 8 & 3.9 \\
\hline Research integrity/research methods & $\begin{array}{l}\text { Strengthening research methods, statistical analysis, quality of research, spin, } \\
\text { identifying gaps in research, validation of a research tool/test, comparison of different } \\
\text { measurement methods }\end{array}$ & 22 & $10 \cdot 8$ \\
\hline Social determinants of health & $\begin{array}{l}\text { Social, economic, environmental factors, health inequalities, socio-economic disparities, } \\
\text { geographical distribution of diseases, food availability, food costs }\end{array}$ & 24 & 11.8 \\
\hline Lifestyle factors & $\begin{array}{l}\text { When the study did not focus on one single lifestyle factor but on several of them (e.g. } \\
\text { physical activity and/or diet and/or smoking and/or alcohol and/or sleeping habits and/ } \\
\text { or screen time) }\end{array}$ & 20 & $9 \cdot 8$ \\
\hline Alcohol & Alcohol & 2 & 1.0 \\
\hline Sleep & Sleep characteristics, sleep duration & 4 & $2 \cdot 0$ \\
\hline Other & Genetics, disability, bone health, falls, mobile health, self-rated health, drug & 17 & $8 \cdot 3$ \\
\hline \multicolumn{4}{|l|}{ Health outcomes studied } \\
\hline CVD & $\begin{array}{l}\text { CVD events, CVD mortality, cardiometabolic risk, endothelial function, cardiovascular } \\
\text { risk factors }\end{array}$ & 64 & $31 \cdot 4$ \\
\hline Obesity & BMI, weight, weight gain, weight management, body composition, waist circumference & 45 & $22 \cdot 1$ \\
\hline Diabetes & Diabetes prevalence, glycaemia, insulin sensitivity, glycosylated $\mathrm{Hb}(\mathrm{HbA1c})$ & 35 & $17 \cdot 2$ \\
\hline Mortality & All-cause mortality & 19 & 9.3 \\
\hline Cancer & Cancer cases, cancer mortality & 6 & 2.9 \\
\hline Hydration & Fluid intake, hydration status, body fluid balance, thirst & 4 & 2.0 \\
\hline
\end{tabular}

${ }^{\star}$ The percentages do not add to 100 as each publication could be coded with more than one topic. 
thirty-three out of the forty-four sponsorships; eleven sponsorships were therefore excluded from our analysis. Some PI were awarded multiple grants, thus we identified twenty-six different PI for thirty-three sponsored projects.

\section{Mars}

Several collaborations were mentioned on the company website but unlike Coca-Cola, Mars did not provide a detailed list of funding awarded to different organizations and institutions. Therefore, we searched the company's research facilities' websites. After excluding the facilities whose research areas did not meet our inclusion criteria (e.g. the WALTHAM Centre for Pet Nutrition), we focused on the Mars Center for Cocoa Health Science ${ }^{(23)}$. Its website contained a 'Partnerships' section that listed five partnerships, four of which met our inclusion criteria. For each project, we found a description of the topic, the partner institution and the PI; however, the amount of funding from Mars was not disclosed.

\section{Publications resulting from the sponsored research projects}

After screening the publications retrieved from PubMed for each of the thirty PI, we included 217 publications considered to be related to one of the thirty-seven included projects (thirty-three from Coca-Cola, four from Mars). Thirteen publications were excluded because they were duplicates of publications containing multiple PI as authors. Therefore, 204 individual publications were further analysed (Fig. 1). The average number of publications per sponsored project was six; five projects had none. Out of the 204 included publications, 141 (69.1\%) disclosed funding from Coca-Cola or Mars, while sixty-three (30.9\%) had no disclosure of funding sources or authors' conflicts of interest with the company. The rate of non-disclosure was similar among the two companies $(30.0 \%$ in the CocaCola sample, $37.5 \%$ in the Mars sample). An employee of Coca-Cola or Mars was a co-author in thirteen $(6.4 \%)$ publications.

\section{Study characteristics of publications}

As Table 2 shows, observational studies were the most frequent study design ( $n$ 120, 58.8\%), followed by

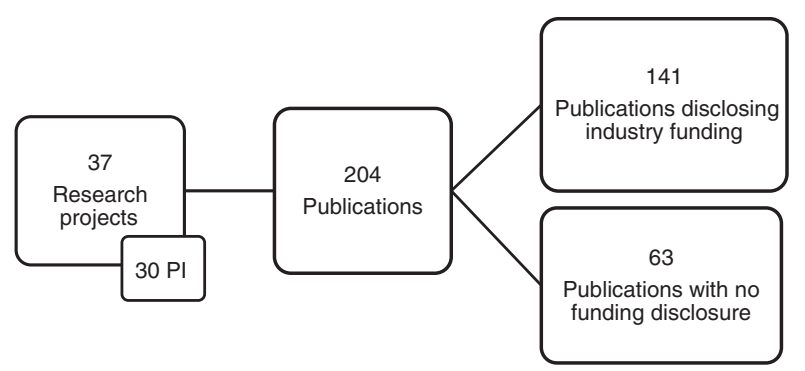

Fig. 1 Flowchart of publications resulting from research projects related to human health funded by Coca-Cola and Mars, identified through a PubMed search, December 2016 narrative reviews ( $n$ 31, 15.2\%). The included articles were published in 103 different journals. The top journals were Medicine and Science in Sports and Exercise with thirteen publications (6.4\%), followed by Nutrients with eleven articles (5.4\%).

\section{Research topics of publications}

Most of the publications resulting from the sponsored research projects focused on physical activity ( $n$ 83, $40 \cdot 7 \%)$ and health outcomes such as CVD ( $n$ 64, 31.4\%), obesity ( $n$ 45, 22.1\%) and diabetes ( $n$ 35, 17.2\%; Table 3). The largest number of studies focused on nutrients ( $n$ 45, 22.1\%), while food groups and dietary patterns were considered in $2.5 \%(n 5)$ and $2.0 \%(n 4)$ of the publications, respectively. Highly processed foods (i.e. foods that are constructed primarily out of processedreconstituted materials) were analysed in $10 \cdot 8 \%$ of the studies.

Twenty-two publications (10.8\%) did not focus on specific research topics such as nutrition or physical activity, but instead focused on the process of conducting research. These papers focused on research integrity (e.g. reproducibility, bias) or research methods (e.g. research quality, statistical analysis, spin, validation of research tools). We report two examples below:

\section{'We systematically assessed the quality of published reviews on sugar-sweetened beverages (SSBS) and bealth, which is a controversial topic that is impor- tant to public bealth.' ${ }^{(24)}$}

The study concluded that systematic methods to report and interpret the evidence were underused in the included reviews.

'The goal of the study was to determine the extent to which authors present overreaching statements in the obesity and nutrition literature, and whether journal, author, or study characteristics are associated with this practice.'(25)

The study found that $8.9 \%$ of the included studies had overreaching information and the prevalence was higher in unfunded studies and in those with a smaller number of co-authors. The authors concluded with some suggestions to reduce the prevalence of this phenomenon in the scientific literature.

Both these studies disclosed the support from the CocaCola Company.

It is worth mentioning that the publications from Mars were a small proportion of the total sample $(11 \cdot 8 \%, n 24)$ and had a different distribution of research topics; for example, $95 \cdot 8 \%$ ( $n$ 23) of the studies focused on nutrients while only $4 \cdot 2 \%(n 1)$ addressed physical activity.

\section{Conclusions in publications}

Of the forty-seven $(23.0 \%)$ articles that studied a product or a component marketed by the sponsor, thirty-three 
(70.2\%) had a conclusion that favoured the sponsor's product such as:

'This dietary intervention study provides evidence that regular CF [cocoa flavanol] consumption can reduce some measures of age-related cognitive dysfunction, possibly through an improvement in insulin sensitivity. These data suggest that the habitual intake of flavanols can support bealthy cognitive function with age.,(26)

Two ( $4.3 \%$ ) had a conclusion that did not favour the sponsor's product such as:

'We bypothesised that the beverage [a fortified diet cola beverage] also would result in weight loss and that there would be a synergistic effect between the $O B W M$ [online behavioural weight management programme] and the study beverage, but this was not the case.'(27)

Twelve (25.6\%) were coded as neutral or did not have a conclusion that could be interpreted.

\section{Discussion}

\section{Main findings}

The information available on the food companies' websites did not provide sufficient detail for a comprehensive analysis of the extent of industry sponsorship of academic research. Only two companies provided a list of research projects that met our inclusion criteria. Coca-Cola- and Mars-sponsored research projects were likely to be published. The research topics of the resulting publications showed a concentration on nutrient-specific research questions and on non-nutrition related topics. As discussed below, these findings have both policy and practical implications.

\section{Transparency}

A detailed list of funded projects for academic research was not available for most of the companies. This might be due to some companies focusing primarily on in-house research, rather than external research with universitybased academics. In addition, most of the funding disclosed on the websites was for community projects, not research. Most of the data obtained were from Coca-Cola. This could be due to the company's pledge to be more transparent about its investments in scientific research following criticism that exposed the financial ties between Coca-Cola and the Global Energy Balance Network, a US non-profit organization set up to combat obesity ${ }^{(13)}$. However, it is worth mentioning that concerns have been raised about the completeness of the information Coca-Cola discloses ${ }^{(2,28)}$.
The industry-funded projects were likely to be published, with an average of six publications per project across a wide variety of journals. However, five of the thirty-seven projects resulted in no publications. Since our search was conducted up to December 2016, it is possible that some publications will result from those projects in the future. However, it is also possible that the research findings were not published because they were not favourable to the sponsor, a phenomenon known as 'publication bias'(29). Or, companies may fund academic research with the intention to use the findings in position statements, pamphlets for policy makers or marketing materials for consumers, rather than publish in the scientific literature ${ }^{(11)}$. Mechanisms to reduce publication bias like those already implemented in clinical research (e.g. study registries, open access data) should be considered also for observational studies that were the most frequent study design in our sample.

The majority of publications resulting from the industryfunded projects disclosed industry sponsorship, and about a third of publications did not disclose any form of financial support. While there is a possibility that these publications were not industry-funded, it is equally possible that they were and did not state the funding source. This phenomenon has already been reported in other fields; for example, tobacco companies funded organizations that did not disclose the true extent of industry sponsorship of their activities ${ }^{(30)}$. Although the majority of journals require the disclosure of funding sources and authors' conflicts of interest, there is still a reporting gap as this practice relies on self-report ${ }^{(31,32)}$.

\section{The research agenda}

Our analysis shows that the food industry is likely to sponsor studies focusing on nutrients. For research focusing on dietary intake, the level of analysis mostly involved a reductionist approach to specific nutrients or components rather than a broader focus on foods and dietary patterns. These findings are consistent with previous work that examined the research topics in a sample of published studies on nutrition and obesity ${ }^{(17)}$. Nutritional reductionism has already been described as a technique that the food industry might use to promote its products using nutrient content claims ${ }^{(1,16)}$.

Our findings also show that the food industry is likely to fund research on non-nutrition related topics and their association with health outcomes. More than $40 \%$ of the studies focused on physical activity/sedentary behaviours while about $10 \%$ focused on highly processed foods. Both companies included in our analysis market highly processed products. This phenomenon, already described as 'physical activity diversion'(19), confirms previous findings from investigative journalism that exposed how Coca-Cola funded academic investigators with the aim of shaping obesity research to shift attention from the role of 
sugar-sweetened beverages in obesity to the role of sedentary behaviour ${ }^{(13)}$. A recent analysis of 389 articles funded by Coca-Cola has revealed a similar distribution of research topics, with a particular emphasis on physical activity and on the concept of energy balance ${ }^{(28)}$.

About $10 \%$ of the publications focused on research integrity or research methods. Shaping the debate around scientific methods can be another strategy that corporations use for their benefit. Analyses of tobacco industry documents exposed the attempts by Philip Morris to influence the standards for scientific research through public relations campaigns about 'sound science' and 'good epidemiological practices'(33,34). By suggesting changes in standards for statistical significance and causality or questioning certain methodologies, such as metaanalysis, corporate sponsored studies can raise doubts about the methods used in non-industry sponsored research.

Only a small proportion of studies focused on a product made by the sponsoring company, but the majority of these publications had conclusions that favoured the sponsor's product. This is similar to other research in the pharmaceutical and nutrition areas that found an association between research sponsorship and conclusions that favour the sponsor's products ${ }^{(8,12)}$.

Obesity, and associated diseases such as CVD, were often the focus of the research funded by the companies in our study. As some authors point out, food companies are often 'rebranding themselves as nutrition companies', offering knowledge and expertise not only in food production but also in global public health problems such as obesity $^{(35)}$. However, owing to their mission to increase profits, food companies tend to frame public health problems and their solutions in ways that are less threatening to their interests ${ }^{(36)}$. This is why, for example, obesity is portrayed as a problem of poor dietary choices and lack of physical activity, and not the result of a food environment that constantly exposes people to ultra-processed drinks and foods ${ }^{(1)}$.

Although a focus on research topics that could maximize profits is expected from corporations, these results are alarming from a public health perspective. First, the influence on the research agenda gives the industry the potential to affect policy making by influencing the type of evidence that is available to inform that process. Second, as our focus was on industry-funded projects with academic researchers, these results show how industry sponsorship might shift the academic research agenda away from important public health problems.

\section{Limitations}

There were several limitations to the current study. If a company had multiple branches, we only analysed the websites of the ones located in regions where English is a primary, official language. This led to the exclusion of branches located in low- and middle-income countries, which have been identified as emerging markets for Big Food $^{(37)}$. Additional research is needed to explore whether this market penetration and the mass-marketing campaigns accompanying it are also associated with strategic partnerships with researchers in low- and middle-income countries. We relied on information disclosed by companies on their websites and could not verify the accuracy and completeness of the data. As transparency about research varied by company, and sometimes also by regional branches of the same company, we were able to include only two companies in our analysis. Moreover, we might have missed some publications resulting from the industry-funded research projects because, first, the search was limited to only one database and, second, we searched only for the name of the PI for collaborative projects involving multiple institutions and collaborators. Tracking the publications was difficult because sufficient information on the sponsored study topic was sometimes missing from the website. It was difficult to interpret some of the disclosed project titles and match them with the publications: some were vague; others were more descriptive, but still broad. In these cases, we decided to take a more inclusive approach by including any articles that appeared to be related to the project. Moreover, when the same PI received multiple grants on similar topics (this happened for the Coca-Cola North America list), it was difficult to attribute each publication to the appropriate project and thus errors could have been made when attributing publications to a particular industryfunded project.

\section{Conclusion}

Our study shows the potential for corporate sponsorship to influence the research agenda by focusing the funded projects and resulting scientific publications on certain research topics. The analysis of publications resulting from Coca-Cola- and Mars-sponsored research showed that among the studies that had a nutrition focus, single nutrients, a component that can be manipulated by food companies, were often the focus of the research. Moreover, food industry-funded research can distract from nutrition as a health issue by diverting public and policy attention to physical activity. Corporate influence on the research agenda needs to be routinely taken into account by decision makers who want to consider the full body of evidence on a topic; the evidence may indeed be skewed towards solutions that favour food industry interests. The influence on the research agenda might allow the food industry to narrowly frame public health problems and policy solutions as needing technological intervention rather than behavioural or system-wide interventions. 
Finally, the potential shift of priorities in research is only one of the ethical implications of the relationship between industry and university. Apart from greater transparency and full disclosure, clear institutional policies on industry sponsorship and conflicts of interest are needed to preserve research integrity and independence.

\section{Acknowledgements}

Financial support: The work was partially funded by a University of Sydney School of Pharmacy summer scholarship. The funding source had no role in the design and conduct of the study; collection, management, analysis and interpretation of the data; preparation, review and approval of the manuscript; or the decision to submit the manuscript for publication. Conflict of interest: None. Authorship: A.F., T.J.H., L.A.B. conceived the study and designed the data collection tool. A.F. and T.J.H. collected the data. A.F. wrote the first draft of the paper. T.J.H. and L.A.B. contributed to the writing of the paper and approved the final version. Ethics of human subject participation: Not applicable.

\section{Supplementary material}

To view supplementary material for this article, please visit https://doi.org/10.1017/S1368980018002100

\section{References}

1. Nestle M (2013) Food Politics: How the Food Industry Influences Nutrition and Health, 1st ed. Berkeley, CA: University of California Press.

2. Matos Serodio P, Stuckler D, Mckee M et al. (2016) OP76 Corporate funding of scientific research: a case study of Coca-Cola. J Epidemiol Community Health 70, A $42-\mathrm{A} 43$

3. Nestle M (2016) Corporate funding of food and nutrition research: science or marketing? JAMA Intern Med 176, 13-14.

4. Australian Government (2015) National Innovation and Science Agenda Report. https://www.innovation.gov.au/ page/national-innovation-and-science-agenda-report (accessed May 2018).

5. Singh A \& Singh S (2005) The connection between academia and industry. Mens Sana Monogr 3, 5-35.

6. Barnes DE \& Bero LA (1998) Why review articles on the health effects of passive smoking reach different conclusions. JAMA 279, 1566-1570.

7. Bero L, Oostvogel F, Bacchetti P et al. (2007) Factors associated with findings of published trials of drug-drug comparisons: why some statins appear more efficacious than others. PLoS Med $\mathbf{4}$, e184.

8. Lundh A, Lexchin J, Mintzes B et al. (2017) Industry sponsorship and research outcome. Cochrane Database Syst Rev 2, MR000033.

9. Vedula SS, Bero L, Scherer RW et al. (2009) Outcome reporting in industry-sponsored trials of gabapentin for off-label use. N Engl J Med 361, 1963-1971.

10. Vera-Badillo FE, Shapiro R, Ocana A et al. (2013) Bias in reporting of end points of efficacy and toxicity in randomized, clinical trials for women with breast cancer. Ann Oncol 24, 1238-1244.

11. Barnes DE \& Bero LA (1996) Industry-funded research and conflict of interest: an analysis of research sponsored by the tobacco industry through the Center for Indoor Air Research. J Health Polit Policy Law 21, 515-542.

12. Chartres N, Fabbri A \& Bero LA (2016) Association of industry sponsorship with outcomes of nutrition studies: a systematic review and meta-analysis. JAMA Intern Med 176, 1769-1777.

13. O'Connor A (2015) Coca-Cola funds scientists who shift blame for obesity away from bad diets. The New York Times, 9 August 2015. https://well.blogs.nytimes.com/2015/08/09/ coca-cola-funds-scientists-who-shift-blame-for-obesity-awayfrom-bad-diets/?_r=0 (accessed May 2017).

14. Kearns CE, Glantz SA \& Schmidt LA (2015) Sugar industry influence on the scientific agenda of the National Institute of Dental Research's 1971 National Caries Program: a historical analysis of internal documents. PLoS Med 12, e1001798.

15. Kearns CE, Schmidt LA \& Glantz SA (2016) Sugar industry and coronary heart disease research: a historical analysis of internal industry documents. JAMA Intern Med 176, $1680-1685$.

16. Scrinis G (2013) Nutritionism: The Science and Politics of Dietary Advice. New York: Columbia University Press.

17. Fabbri A, Chartres N, Scrinis G et al. (2017) Study sponsorship and the nutrition research agenda: analysis of randomized controlled trials included in systematic reviews of nutrition interventions to address obesity. Public Health Nutr 20, 1306-1313.

18. Fabbri A, Chartres N \& Bero LA (2017) Study sponsorship and the nutrition research agenda: analysis of cohort studies examining the association between nutrition and obesity. Public Health Nutr 20, 3193-3199.

19. Nestle M (2016) Soda Politics: Taking on Big Soda (and Winning). New York: Oxford University Press.

20. Oxfam (2014) These 10 companies make a lot of the food we buy. Here's how we made them better. https://www. oxfamamerica.org/explore/stories/these-10-companies-makea-lot-of-the-food-we-buy-heres-how-we-made-them-better/ (accessed February 2017).

21. Oxfam (2013) Behind the brands: Food justice and the 'Big 10' food and beverage companies. https://www.oxfam.org/ sites/www.oxfam.org/files/bp166-behind-the-brands-260213en.pdf (accessed May 2018).

22. Coca Cola Company (2016) Our Actions and Way Forward (7 October 2015). http://transparency.coca-colacompany. com/ (accessed February 2017).

23. Mars Center for Cocoa Health Science (2017) Homepage. http://www.marscocoascience.com (accessed March 2017).

24. Weed DL, Althuis MD \& Mink PJ (2011) Quality of reviews on sugar-sweetened beverages and health outcomes: a systematic review. Am J Clin Nutr 94, 1340-1347.

25. Menachemi N, Tajeu G, Sen B et al. (2013) Overstatement of results in the nutrition and obesity peer-reviewed literature. Am J Prev Med 45, 615-621.

26. Mastroiacovo D, Kwik-Uribe C, Grassi D et al. (2015) Cocoa flavanol consumption improves cognitive function, blood pressure control, and metabolic profile in elderly subjects: the Cocoa, Cognition, and Aging (CoCoA) Study - a randomized controlled trial. Am J Clin Nutr 101, 538-548.

27. Haddock CK, Poston WSC, LaGrotte C et al. (2014) Findings from an online behavioural weight management programme provided with or without a fortified diet beverage. Br J Nutr 111, 372-379.

28. Serôdio PM, McKee M \& Stuckler D (2018) Coca-Cola - a model of transparency in research partnerships? A network analysis of Coca-Cola's research funding (2008-2016). Public Health Nutr 21, 1594-1607. 
29. Dickersin K (1990) The existence of publication bias and risk factors for its occurrence. JAMA 263, 1385-1389.

30. Schick SF \& Glantz SA (2007) Old ways, new means: tobacco industry funding of academic and private sector scientists since the Master Settlement Agreement. Tob Control 16, 157-164.

31. Forsyth SR, Odierna DH, Krauth D et al. (2014) Conflicts of interest and critiques of the use of systematic reviews in policymaking: an analysis of opinion articles. Syst Rev $\mathbf{3}, 122$.

32. Ruff K (2015) Scientific journals and conflict of interest disclosure: what progress has been made? Environ Health 14, 45.

33. Baba A, Cook DM, McGarity TO et al. (2005) Legislating 'sound science': the role of the tobacco industry. Am J Public Health 95, Suppl. 1, S20-S27.
34. Ong EK \& Glantz SA (2001) Constructing 'sound science' and 'good epidemiology': tobacco, lawyers, and public relations firms. Am J Public Health 91, 1749-1757.

35. Plos Medicine Editors (2012) PLoS Medicine series on Big Food: the food industry is ripe for scrutiny. PLoS Med $\mathbf{9}$, e1001246.

36. Simon M (2011) Pepsico and public health: is the nation's largest food company a model of corporate responsibility or master of public relations? CUNY Law Rev 15, issue 1, doi: 10.31641/clr150102.

37. Stuckler D \& Nestle M (2012) Big food, food systems, and global health. PLoS Med 9, e1001242. 